\title{
Diagnostic delays in vasculitis and factors associated with time to diagnosis
}

\author{
Antoine G. Sreih', Keri Cronin', Dianne G. Shaw², Kalen Young², Cristina Burroughs³, Joyce Kullman², \\ Kirthi Machireddy ${ }^{1}$, Carol A. McAlear ${ }^{1}$, Peter A. Merkel ${ }^{1,4^{*}}$ and for the Vasculitis Patient-Powered Research \\ Network ${ }^{4}$
}

\begin{abstract}
Background: Patients with vasculitis, a set of rare diseases, encounter delays in obtaining an accurate diagnosis which can lead to substantial morbidity and increased mortality. This study sought to describe the diagnostic journey of patients with vasculitis and identify factors associated with time to diagnosis.

Methods: Patients with vasculitis enrolled in an online registry completed a two-stage study: Stage 1: survey of open-ended questions about patients' diagnostic journeys and perceived factors associated with rapid or delayed diagnosis; Stage 2: survey with specific questions based on data from Stage 1 and additional investigator-identified factors.

Results: 375 patients with vasculitis participated in Stage 1; 456 patients participated in Stage 2. 85\% of patients were seen by a healthcare provider within 3 months of the onset of symptoms. The median time to diagnosis of vasculitis was 7 months. 313/456 (73\%) of patients were misdiagnosed initially. 40\% of diagnoses were made in a hospital setting; $2 \%$ of diagnoses were made at a specialized vasculitis center. $60 \%$ of patients had at least 1 visit to an emergency room prior to diagnosis. Unemployment, time to travel to a medical center $>1 \mathrm{~h}$, initial misdiagnosis, and delays in seeing a specialist were all associated with longer times to diagnosis. 373/456 (82\%) of patients reported that a delayed diagnosis had negative consequences on their health.

Conclusion: Patients with vasculitis encounter substantial delays in achieving an accurate diagnosis and these delays are associated with negative health consequences. Both patient-related factors and healthcare-related factors are associated with diagnostic delays.
\end{abstract}

Keywords: Vasculitis, Diagnosis, Patient-reported data

\section{Background}

Vasculitis is a heterogeneous group of rare diseases that affect blood vessels of different sizes and may result in organ failure or death. These disorders often have clinical presentations similar to other more common diseases and patients are often initially misdiagnosed and treated for other conditions prior to establishing the

\footnotetext{
*Correspondence: pmerkel@upenn.edu

${ }^{1}$ Division of Rheumatology, University of Pennsylvania, White Building, 5th Floor, 3400 Spruce Street, Philadelphia, PA 19104, USA

Full list of author information is available at the end of the article
}

appropriate vasculitis diagnosis. Such delays in diagnosis can negatively impact clinical outcomes and frequently result in increased morbidity and mortality for all forms of vasculitis. Reducing delays in diagnosis can help alleviate this negative impact and improve clinical outcomes. Prior studies on diagnostic delays focused on single forms of vasculitis [1-4] or on patients seen at a tertiary care hospital [5] and were developed without patient engagement. This study aimed to gain a better understanding of the journey that patients with any form of vasculitis go through before receiving their diagnosis original author(s) and the source, provide a link to the Creative Commons licence, and indicate if changes were made. The images or other third party material in this article are included in the article's Creative Commons licence, unless indicated otherwise in a credit line to the material. If material is not included in the article's Creative Commons licence and your intended use is not permitted by statutory regulation or exceeds the permitted use, you will need to obtain permission directly from the copyright holder. To view a copy of this licence, visit http://creativecommons.org/licenses/by/4.0/. The Creative Commons Public Domain Dedication waiver (http://creativeco mmons.org/publicdomain/zero/1.0/) applies to the data made available in this article, unless otherwise stated in a credit line to the data. 
and identify factors associated with those delays. Patients were involved in the development, review, approval, and conduct of this study.

\section{Methods}

The study had 3 aims: (1) identify the average amount of time that elapses between the onset of the first symptoms of vasculitis to the time of diagnosis; (2) identify factors associated with time to diagnosis of vasculitis; and (3) gain an understanding of patients' perceptions of the consequences that result from delays in establishing a diagnosis of vasculitis. The study was conducted using a combination of qualitative and quantitative methods to understand patients' experiences with working towards obtaining a diagnosis of vasculitis. The patients invited to join the study were members of the Vasculitis PatientPowered Research Network (VPPRN, www.vpprn.org) with self-reported vasculitis. The VPPRN, founded in 2014, is an online registry for patients with all forms of vasculitis who are interested in participating in clinical research studies. The study was executed via a two-stage survey:

\section{Stage 1}

This stage involved a short, open-ended qualitative survey asking patients to write in the factors they believed contributed to their diagnosis of vasculitis. The survey was administered to a series of randomly selected samples of patients until data saturation was reached. Data saturation was determined when a sample size was reached that was large enough for qualitative concept elicitation to allow for a richly textured understanding of the factors believed to contribute to a diagnosis of vasculitis and additional data would not meaningfully change the main results. Patients with diagnoses that had not been confirmed by a physician were excluded from analysis. Physician diagnosis of vasculitis was patientreported. Incomplete responses were not included in the final analysis. The qualitative data from the Stage 1 survey responses was analyzed with NVivo software (QSR International Pty Ltd., Melbourne).

The data was examined using an inductive approach to coding the data by identifying distinct concepts and categories that emerged across several of the patients' open-ended responses. This information enabled the breakdown of the responses into first-level concepts and second-level categories using a thematic synthesis approach. Responses were then reexamined to confirm that the categories accurately depicted the patient responses and to identify relationships among the concepts and categories. Nodes were then created to represent the emergent themes among concepts and categories. This information was then used to group the responses by speed of diagnosis and type of disease. The disease-specific coding involved calculating the frequency of each node for each of the different diseases.

\section{Stage 2}

The results of the Stage 1 survey and input from health care providers were used to create a second survey. The Stage 2 survey was created using the factors that impacted the time to diagnosis mentioned by patients with the highest frequency. The second survey asked about the date of onset of symptoms and of diagnosis, the chronological order of symptoms experienced before the diagnosis was established, which tests were ordered and when they were completed, the type of providers seen by patients during their journey towards a diagnosis, and the type of provider and test that confirmed the diagnosis. Patients were also asked about other comorbid conditions. The Stage 2 survey is included in Supplementary Material.

Identified factors were classified as either intrinsic or extrinsic factors. Intrinsic factors are patient-related factors, such as the type of symptoms of vasculitis, demographics, socioeconomic status, and patients' beliefs. Extrinsic factors are any factors related to healthcare professionals or health systems, such as access to healthcare and referral patterns. To gain a more complete understanding of patients' access to care, additional questions were asked about specific social determinants of health, including health behaviors, social environment, income, and quality of health services.

This second survey was then reviewed and refined by a survey methodologist and pilot-tested by patient research partners on the VPPRN Research, Innovation, Planning, and Experiments (RIPE) and Recruitment, Education, and Communication (REC) working groups prior to being administered to VPPRN members through the online portal.

Two time periods prior to establishment of a diagnosis were assessed: (1) the pre-encounter interval is the period between the onset of the first symptoms of vasculitis and the initial encounter with a healthcare professional regarding those symptoms; (2) the post-encounter interval is the period between the first encounter with a healthcare provider and the establishment of the correct diagnosis. To minimize recall bias any patients diagnosed more than 5 years before the survey were not included in analysis. The median duration of diagnosis was calculated for all participants and for each sub-type of vasculitis. Discrete data generated by the survey is reported by counts; continuous data is reported by means \pm standard deviation, and interquartile ranges (IQRs). Continuous variables were compared between groups using analysis of variance (ANOVA). 
Univariate and multivariate logistic regression analysis was used to identify factors associated with delays in diagnosis. These factors included sex, age, race, geographic location, distance to closest major institution studying vasculitis, household income, marital status, presence of insurance, presence of co-morbidities, specialist consultation, time to specialist consultation, major testing to establish presence/absence of disease involved, time to obtain major testing, number of alternative diagnoses before vasculitis, and patient-related versus professional/health system-related factors. The Charlson Comorbidity Index was also used as a comorbidity summary measure [6]. All factors that had a statistically significant association with time to diagnosis in the univariate model were included in a multivariate model and analyzed using the forward selection method. All analyses were performed using STATA (StataCorp, College Station, Texas). A p value $\leq 0.05$ was considered to be statistically significant for both the univariate and multivariate model.

An Institutional Review Board reviewed and approved the study and all participants provided informed consent.

\section{Results}

\section{Stage 1 survey results}

Three-hundred and seventy-five patients responded to the initial Stage 1 survey. The majority of patients had a form of ANCA-associated vasculitis (eosinophilic granulomatosis with polyangiitis, granulomatosis with polyangiitis, or microscopic polyangiitis), but also included participants with Behçet's disease, central nervous system vasculitis, cryoglobulinemic vasculitis, giant cell arteritis, IgA vasculitis, polyarteritis nodosa, Takayasu's arteritis, and urticarial vasculitis.
The responses indicated that while some patients were promptly diagnosed, many patients experienced delays in diagnosis with a median time to diagnosis of 7 months.

The responses from the Stage 1 survey helped identify the types of variables that impact the amount of time it takes for a patient to be diagnosed. The results yielded variables that fell into the following categories: type of physician, presenting symptoms, patient disease experience, medical evaluation, patient resources, and medical intervention. The Stage 1 survey results indicated that patients felt that access to specialists and tertiary care had the greatest impact on the speed of their diagnosis. Participants who felt their physician was associated with their delayed diagnosis reported that the physician often lacked knowledge of vasculitis. Patients also attributed delays to their inability to access the appropriate specialist. Patients who felt they were quickly diagnosed with vasculitis often reported that they were able to easily access specialists who were willing to collaborate with other members of a care team, willing to refer the patient to other providers, and willing to run diagnostic tests.

The results of the Stage 1 survey were used to inform the design of the Stage 2 survey. The draft Stage 2 survey was pilot-tested by the VPPRN patient-partners and modified as needed before being administered electronically to patients through the VPPRN patient portal.

\section{Stage 2 survey results}

The Stage 2 survey was taken by 456 patients (Tables 1 and 2, Fig. 1). The mean age \pm standard deviation was $56 \pm 15$ years, with $72 \%$ female, 95\% Caucasian, $1 \%$ African American, 3\% Asian, and 1\% other race. Three percent of patients were Hispanic. Eighty percent of patients were from the United States. The median time

Table 1 Study subject demographics by disease

\begin{tabular}{|c|c|c|c|c|}
\hline Disease type & $\begin{array}{l}\text { Number of } \\
\text { patients }\end{array}$ & Mean age \pm SD (median) & $\begin{array}{l}\text { Female } \\
\mathrm{N}(\%)\end{array}$ & $\begin{array}{l}\text { Caucasian } \\
\mathrm{N}(\%)\end{array}$ \\
\hline Behçet's disease & 17 & $45 \pm 13(41)$ & $15(88 \%)$ & $15(94 \%)$ \\
\hline Central nervous system vasculitis & 15 & $53 \pm 11(55)$ & $12(80 \%)$ & $13(87 \%)$ \\
\hline Cryoglobulinemic vasculitis & 15 & $63 \pm 14(67)$ & $13(87 \%)$ & $14(93 \%)$ \\
\hline Eosinophilic granulomatosis with polyangiitis & 58 & $59 \pm 12(60)$ & $40(69 \%)$ & $54(93 \%)$ \\
\hline Giant cell arteritis & 26 & $70 \pm 9(73)$ & $20(77 \%)$ & $24(92 \%)$ \\
\hline Granulomatosis with polyangiitis & 169 & $56 \pm 15(59)$ & $110(65 \%)$ & $164(98 \%)$ \\
\hline IgA-vasculitis & 18 & $49 \pm 19(53)$ & $12(67 \%)$ & $17(94 \%)$ \\
\hline Microscopic polyangiitis & 53 & $57 \pm 14(61)$ & $43(81 \%)$ & $52(98 \%)$ \\
\hline Polyarteritis nodosa & 21 & $47 \pm 20(50)$ & $11(52 \%)$ & $19(90 \%)$ \\
\hline Takayasu's arteritis & 21 & $43 \pm 18(38)$ & $20(95 \%)$ & $19(90 \%)$ \\
\hline Urticarial vasculitis & 15 & $57 \pm 12(60)$ & $12(80 \%)$ & $15(100 \%)$ \\
\hline Other & 28 & $54 \pm 14(58)$ & $22(79 \%)$ & $26(93 \%)$ \\
\hline Total for all types of vasculitis & 456 & $56 \pm 15(59)$ & $330(72 \%)$ & $432(95 \%)$ \\
\hline
\end{tabular}


Table 2 Study subject demographics for entire study population

\begin{tabular}{|c|c|}
\hline Demographics & $\mathrm{N}=456(\%)$ \\
\hline \multicolumn{2}{|l|}{ Sex } \\
\hline Female & $330(72 \%)$ \\
\hline Male & $126(28 \%)$ \\
\hline \multicolumn{2}{|l|}{ Race } \\
\hline American Indian or Alaskan Native & $7(2 \%)$ \\
\hline Asian & $13(3 \%)$ \\
\hline Black or African American & $6(1 \%)$ \\
\hline Native Hawaiian or Pacific Islander & $1(0 \%)$ \\
\hline White & $390(95 \%)$ \\
\hline Multiple races & $1(0 \%)$ \\
\hline Decline to answer & 0 \\
\hline \multicolumn{2}{|l|}{ Ethnicity } \\
\hline Hispanic, Latino, or of Spanish Origin & $12(3 \%)$ \\
\hline Not Hispanic, Latino, or of Spanish Origin & $418(92 \%)$ \\
\hline Do not know & $16(4 \%)$ \\
\hline Missing & $2(0 \%)$ \\
\hline Decline to answer & $8(2)$ \\
\hline \multicolumn{2}{|l|}{ Location } \\
\hline USA or Canada & $370(81 \%)$ \\
\hline Outside USA or Canada & $86(19 \%)$ \\
\hline Level of education & $\mathrm{N}=456(\%)$ \\
\hline Grade 8 or less & $19(4 \%)$ \\
\hline Some high school & $21(5 \%)$ \\
\hline High school graduate or GED & $35(8 \%)$ \\
\hline Some college. No bachelor's degree & $142(31 \%)$ \\
\hline Bachelor's degree & $111(24 \%)$ \\
\hline Post-bachelor's degree awarded & $118(26 \%)$ \\
\hline Decline to answer & $8(2 \%)$ \\
\hline \multicolumn{2}{|l|}{ Employment status } \\
\hline Disabled (unable to work) & $16(4 \%)$ \\
\hline Student (not working) & $45(10 \%)$ \\
\hline Employed with income & $294(64 \%)$ \\
\hline Employed without income (volunteer) & $3(1 \%)$ \\
\hline Homemaker & $17(4 \%)$ \\
\hline Retired & $64(14 \%)$ \\
\hline Decline to answer & $5(1 \%)$ \\
\hline \multicolumn{2}{|l|}{ Household income (US Dollars) } \\
\hline Less than $\$ 9999$ & $24(5 \%)$ \\
\hline$\$ 10,000$ to $\$ 29,000$ & $43(9 \%)$ \\
\hline$\$ 30,000$ to $\$ 39,000$ & $50(11 \%)$ \\
\hline$\$ 50,000$ to $\$ 99,000$ & $126(28 \%)$ \\
\hline
\end{tabular}

to diagnosis of vasculitis was 7 months. Of the patients sampled, $50 \%$ were diagnosed within one year and $75 \%$ were diagnosed within two years. The time that elapsed prior to diagnosis varied for each of the different types of vasculitis. Patients with IgA-vasculitis experienced the shortest diagnosis time with a median of 1 month while patients with Behçet's disease experienced the longest time to diagnosis with a median of 205 months (Fig. 2).

The majority of patients with vasculitis (73\%) were initially misdiagnosed (Table 3 ). The most common misdiagnoses were infection (33\%) and autoimmune 


\begin{tabular}{|c|c|c|c|c|c|c|c|}
\hline & \multicolumn{5}{|c|}{2,400 patients from the VPPRN were invited to participate in Stage 1 and Stage 2 of Journey } & & \\
\hline & \multicolumn{5}{|c|}{ Stage 1 qualitative survey was used to inform the Stage 2 survey } & & \\
\hline \multicolumn{4}{|c|}{375 Participants completed the Stage 1 Qualitative Survey } & \multicolumn{4}{|c|}{456 Participants Completed the Stage 2 Survey } \\
\hline Oisease Trpe & $\begin{array}{c}\text { \%of total } \\
\text { completed Stage } \\
1 \text { Survers } 8 y \\
\text { Oisease }(N=375)\end{array}$ & $\begin{array}{l}\text { \% of patients } \\
\text { who felt they } \\
\text { had a fast } \\
\text { diagnosis by } \\
\text { disease }\end{array}$ & $\begin{array}{c}\text { Xof patients who felt } \\
\text { they had a delayed } \\
\text { diagnosis }\end{array}$ & Disease Type & $\begin{array}{l}\text { Xof total } \\
\text { Stage } 2 \text { survey } \\
\text { by disease } \\
\text { (N=456) }\end{array}$ & $\begin{array}{l}\text { Time to Oiagnosis } \\
\text { Median } \\
\text { Means SO } \\
\text { (Months) }\end{array}$ & $\begin{array}{l}\text { Range of } \\
\text { time to } \\
\text { Diagnosis } \\
\text { (Months) }\end{array}$ \\
\hline Behcet's Disease & 3x & $\alpha x$ & $100 \mathrm{~s}$ & Behcet's Disease & $4 \%$ & $\begin{array}{c}205 \\
244 \pm 191\end{array}$ & $3.6-619$ \\
\hline Central Nervous System Vasculitis & $4 \times$ & sox & $50 \%$ & Central Nervous Spstem Vasculitis & $3 \%$ & $\begin{array}{c}1 \\
8 \pm 13\end{array}$ & $0.0-38$ \\
\hline Cryoblobulinemic Vascultis & $2 \mathrm{x}$ & $100 \%$ & $0 \%$ & Cryoblobulinemic Vasculatis & $3 \%$ & $\begin{array}{c}9 \\
34 \pm 68 \\
\end{array}$ & $0.0-233$ \\
\hline $\begin{array}{l}\text { Cosinophilic Granulomatosis with } \\
\text { Polvangitis }\end{array}$ & $9 \mathrm{x}$ & $25 \%$ & $75 \%$ & $\begin{array}{l}\text { Cosinophilic Granulomatosis with } \\
\text { Polyangitis }\end{array}$ & 135 & $\begin{array}{c}16 \\
60: 100\end{array}$ & $0.0-432$ \\
\hline Giant Cell (Temporal) Arteritis & $4 \times$ & sow & $50 \%$ & Giant Cell (Temporal) Arteritis & $6 \%$ & $\begin{array}{c}2 \\
21: 79\end{array}$ & $0.0-384$ \\
\hline Granulomatosis with Polvangitis & $47 \%$ & $39 \%$ & $61 \%$ & Granulomatosis with polvangitis & $37 x$ & $\begin{array}{c}6 \\
21 \div 38\end{array}$ & $0.0-193$ \\
\hline IgA Vasculitis & $2 x$ & $25 \%$ & $75 \%$ & IgA Vasculitis & $4 \%$ & $\begin{array}{c}1 \\
3 \pm 5\end{array}$ & $0.0-17$ \\
\hline Microscopic Polyangitis & $12 \%$ & $40 \%$ & $\cos$ & Microscopic Polvangïtis & $12 \mathrm{x}$ & $\begin{array}{c}6 \\
32 \pm 57\end{array}$ & $1.2-244$ \\
\hline Othet/Suspected Disgnosis & s* & $\alpha x$ & $100 \mathrm{~s}$ & Other/Suspected Diagnosis & $5 \%$ & $\begin{array}{c}10 \\
21 \pm 31 \\
\end{array}$ & $0.0-108$ \\
\hline Polvarteritis Nodoss & $4 \times$ & $33 \%$ & 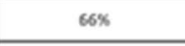 & Polvarteritis Nodosa & $5 \%$ & $\begin{array}{c}9 \\
24: 42 \\
\end{array}$ & $0.0-160$ \\
\hline Takayasu's Arteritis & s: & $29 \%$ & $71 \%$ & Takayasu's Arteritis & $3 \%$ & $\begin{array}{c}31 \\
68285 \\
\end{array}$ & $0.0-252$ \\
\hline Urticarial Vascultis & 35 & $\alpha x$ & $100 x$ & Urticarial Vascultis & $4 \%$ & $\begin{array}{c}2 \\
95: 201\end{array}$ & $3.6-619$ \\
\hline
\end{tabular}

Fig. 1 Participants in Stages 1 and 2 by Time to Diagnosis and Disease Type

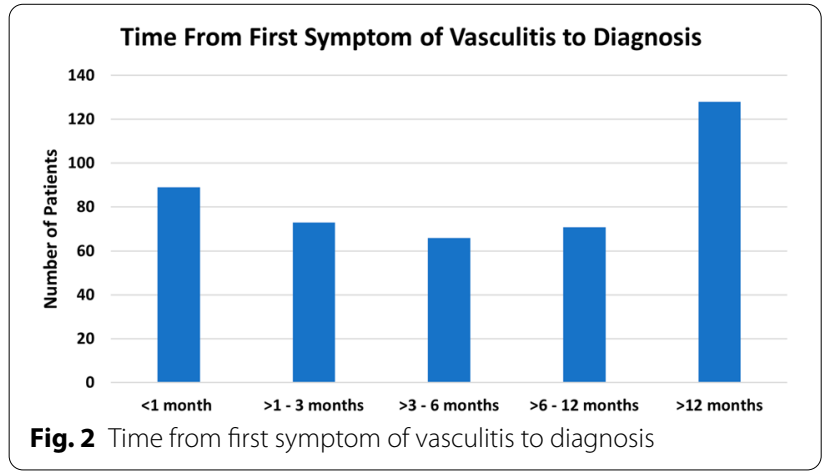

Table 3 Initial diagnosis given before the diagnosis of vasculitis was established

\begin{tabular}{lr}
\hline Initial diagnosis & \\
\hline Infection & $33 \%$ \\
Allergies & $21 \%$ \\
Autoimmune disease & $19 \%$ \\
Not a "real" illness & $11 \%$ \\
Fibromyalgia syndrome & $6 \%$ \\
Cancer & $5 \%$ \\
Other & $49 \%$ \\
\hline
\end{tabular}

disease (29\%). Patient received a median of 5 misdiagnoses before obtaining a correct diagnosis of vasculitis.

An initial misdiagnosis was associated with substantial delays in achieving the correct diagnosis of vasculitis. It took a mean of $3.9 \pm 8$ years for patients who were initially misdiagnosed to obtain their diagnosis of vasculitis versus a mean of $1.58 \pm 5$ years to get a diagnosis of vasculitis for patients who were not initially misdiagnosed.

The symptoms that patients presented with impacted the amount of time that elapsed prior to reaching a diagnosis. Patients with genital ulcers (mean 14.86 \pm 16 years), blood in their stool (mean 9.69 \pm 17 years), scalp tenderness (mean $8.94 \pm 15$ years), mouth sores (mean $8.26 \pm 13$ years), and nausea or digestive issues (mean $6.49 \pm 12$ years) experienced longer delays in diagnosis than other patients (mean $3.3 \pm 7$ years). In contrast, patients with bleeding in their lungs (mean $1.53 \pm 3$ years) achieved a diagnoses more rapidly than other patients (mean $3.3 \pm 7$ years). The techniques used to diagnosis the presenting symptoms also had an impact on the time it took to diagnosis the patient's condition. Patients who had biopsies (mean $2.84 \pm 7$ years), or angiography (mean $2.82 \pm 6$ years), or other radiological 
testing (mean $2.78 \pm 6$ years), were diagnosed faster than patients who did not receive these forms of diagnostic testing ( $3.3 \pm 7$ years).

Prior to achieving a diagnosis of vasculitis $60 \%$ (238, $\mathrm{N}=400$ ) had at least 1 visit to an emergency room (ER) prior to obtaining a diagnosis of vasculitis. Of these patients, 5\% visited the ER more than 10 times before they were finally diagnosed. Of the $40 \%$ of patients who were diagnosed in a hospital, only $5 \%$ were diagnosed in the ER.

The vast majority of patients (91.6\%) were diagnosed by medical specialists. Patients who were initially referred to specialists (mean $2.67 \pm 7$ years) were diagnosed faster than patients who initially were not referred by specialists (mean $4.11 \pm 8$ years).

In a multivariate analysis, factors that were associated with longer delays in diagnosis of vasculitis included being unemployed, having a medical center located farther than $1 \mathrm{~h}$ away, receiving an initial misdiagnosis, and experiencing delays in being able to see a specialist (Table 4).

Of the patients who experienced a delayed diagnosis delays, $82 \%$ reported that the delay had a negative impact on their health. These individuals often reported that the delay led to their condition worsening (55\%), to them losing their job (16\%), and to them becoming disabled (11\%).

Table 4 Factors associated with time to diagnosis of vasculitis

\begin{tabular}{lcr}
\hline Factors & Coefficient (95\% Cl) & p value \\
\hline Patient-related factors & & \\
Time to travel to healthcare site $>1 \mathrm{~h}$ & $2.6(0.6-4.5)$ & $<0.01$ \\
Patient location (North America) & $1.2(-2.0-3.8)$ & 0.76 \\
Single or divorced or widowed & $1.1(-1.0-3.2)$ & 0.29 \\
Household income $>$ \$50,000/year & $-1.5(-4.2-0.6)$ & 0.18 \\
Female & $-1.5(-4.0-0.5)$ & 0.15 \\
Caucasian race & $-1.5(-6.0-3.0)$ & 0.54 \\
Charlson score $>1$ & $-1.5(-3.9-0.4)$ & 0.12 \\
Employed & $-2.4(-4.0--0.4)$ & 0.02 \\
Healthcare-related factors & & \\
Time to see a specialist>1 month & $2.4(0.3-4.6)$ & 0.03 \\
Misdiagnosis & $2.3(0.1-4.5)$ & 0.03 \\
Laboratory studies ordered initially & $0.2(-1.6-2.0)$ & 0.80 \\
Referral delays due to insurance & $-0.3(-2.5-2.5)$ & 0.98 \\
Specialist involved initially & $-1.3(-3.1-0.6)$ & 0.18 \\
\hline
\end{tabular}

The table reports on the results of a multivariate analysis. A positive coefficient indicates a longer time to diagnosis and a negative one indicates a shorter time to diagnosis

Cl: confidence interval; \$: US dollars

\section{Discussion}

Gaining a better understanding of the factors that contribute to delays in the diagnosis of patients with vasculitis creates a more detailed picture of the presentation of this group of diseases. Subsequent mitigation of some of these factors could lead to earlier diagnosis, initiation of appropriate treatment, and ultimately minimizing the negative impact of these organ- and life-threatening diseases.

The present study assessed multiple clinical and health system factors that patients and clinicians identified as potentially leading to delays in obtaining a diagnosis of vasculitis. Factors found significantly associated with a delay in diagnosis included a delay in the patient being seen by a specialist, unemployment, and travel time to a healthcare site. Not surprisingly, an initial misdiagnosis of a disease other than vasculitis also led to delays in diagnosis and such initial misdiagnoses remain quite common. The results from the present study substantively extend prior similar work in vasculitis by studying multiple forms of vasculitis, asking patients about their experiences directly, and engaging patients in the project to help ensure that patients' perspectives on the problem of delays in diagnosis influenced the design of the study [1-4]. The current study also aligns with and extends findings from studies of arriving at diagnoses for other systemic rheumatic diseases and cancer [7-13].

Strengths of this study include the relatively large number of patients from which data were collected and the inclusion of patients' perspectives in the design of the project and the surveys.

There are also limitations to the current study to consider. The study population was derived from the online VPPRN which has a disproportionate number of patients who are female, Caucasian, from North America, and with ANCA-associated vasculitis, thus reducing the full generalizability of the findings. The reliability of patientreported diagnoses of vasculitis is also a potential limitation. However, a recent study in the VPPRN found that patient self-reported diagnosis of ANCA-associated vasculitis to be reliable, with $86-96 \%$ of patients fulfilling the 1990 American College of Rheumatology classification criteria and/or the 2012 Chapel Hill Consensus Conference definitions [14]. Another limitation is selection bias as it may be assumed that patients with a delay in diagnosis would be more likely to participate in a study investigating delays in diagnosis. To minimize this possible effect, the study sought to describe the diagnostic journey of patients with vasculitis from the onset of symptoms to diagnosis and identify factors associated with the time to diagnosis, not just delays. All study recruitment materials and study descriptions emphasized the journey to diagnosis whether fast or delayed. The Stage 1 data 
reported by disease illustrates that the perceived fast or delayed diagnosis varied greatly. The Stage 2 survey data illustrates a similar time to diagnosis when broken down by disease, see Fig. 1 . The percentage of patients who participated in the Stage 1 qualitative study were proportional to those who participated in Stage 2.

\section{Conclusion}

The results of this study illustrate that various factors, both patient-related and healthcare system-related, lead to delays in diagnosis for patients with vasculitis and that these delays can often have a negative impact on patient health and quality of life. Thus, creating ways to accelerate arriving at the correct diagnosis for patients with vasculitis is of the utmost importance. These conclusions indicate that healthcare providers should be better educated on the various ways in which vasculitis can present clinically and what approaches to diagnosis are appropriate in cases of potential vasculitis. Increasing awareness and understanding of vasculitis disorders will hopefully help to streamline the referral process and help eliminate delays in diagnosis.

\section{Abbreviations}

VPPRN: Vasculitis Patient-Powered Research Network.

\begin{abstract}
Acknowledgements
The authors appreciate the following members of the Vasculitis PatientPowered Research Network who reviewed and provided feedback on the survey tools before implementation J. Pablo Abonia, MD; Nita Aines, MSW; Paul Brown, PhD; April Cardone, MBA, MPH; Kristen Crook, Michael Fernandez; James Fingar, PhD; Carol Gorman, MS; Ida Hakkarinen, MS; Sharon Hatfield; Sean Hennessy, PharmD, MSCE, PhD; Paul Jacobsen, PhD; Tanaz Kermani, MD, MS; Marianne Vennitti.

Disclosures: Dr. Merkel reports receiving funds for the following activities in the past 2 years: Consulting: AbbVie, AstraZeneca, Biogen, BoeringherIngelheim, Bristol-Myers Squibb, Celgene, ChemoCentryx, CSL Behring, Forbius, Genentech/Roche, Genzyme/Sanofi, GlaxoSmithKline, InflaRx, Insmed, Jannsen, Kiniksa, Kyverna, Magenta, Novartis, Pfizer, Sparrow, Takeda, Talaris; Research Support: AstraZeneca, Boeringher-Ingelheim, Bristol-Myers Squibb, Celgene, ChemoCentryx, Forbius, Genentech/Roche, Genzyme/Sanofi, GlaxoSmithKline, InflaRx; Royalties: UpToDate.
\end{abstract}

\section{Authors' contributions}

AS, KC, DS, KY designed the study, developed the methodology, performed analysis, helped draft the manuscript, and reviewed the final version of the manuscript. CB, KM, JK, CM, DS, assisted in the development of the study and study questions. They also reviewed and contributed to the final version of the manuscript. PM helped in designing the study, provided oversight of the study, reviewed the study design, help draft and revise the manuscript, and reviewed the final version of the manuscript. All authors read and approved the final manuscript.

\section{Funding}

The Vasculitis Patient-Powered Research Network was supported through a Patient-Centered Outcomes Research Institute (PCORI) award (PPRN1306-04758). The Vasculitis Clinical Research Consortium (VCRC) is part of the Rare Diseases Clinical Research Network (RDCRN), an initiative of the Office of Rare Diseases Research (ORDR), National Center for Advancing Translational Science (NCATS). The VCRC is funded through collaboration between NCATS, and the National Institute of Arthritis and Musculoskeletal and Skin Diseases (U54 AR057319).

\section{Availability of data and materials}

All data generated during and/or analyzed during the current study are not publicly available because the data includes participants' personal health information (e.g. diagnosis, age) but are available from the corresponding author on reasonable request.

\section{Declarations}

Ethics approval and consent to participate

Data Management and Coordinating Center, University of South Florida IRB approval was obtained for the study. Reference number: 00018514 (IRB Approval on January 10, 2018).

\section{Consent for publication}

Not applicable.

\section{Competing interests}

The authors declare that they have no competing interests.

\section{Author details}

${ }^{1}$ Division of Rheumatology, University of Pennsylvania, White Building, 5th Floor, 3400 Spruce Street, Philadelphia, PA 19104, USA. ${ }^{2}$ The Vasculitis Foundation, Kansas City, MO, USA. ${ }^{3}$ Department of Biostatistics, University of South Florida, Tampa, USA. ${ }^{4}$ Vasculitis Patient-Powered Research Network, Philadelphia, PA, USA.

Received: 2 October 2020 Accepted: 30 March 2021

Published online: 21 April 2021

\section{References}

1. Poulton C, Nachman P, Hu Y, McGregor J, Jennette J, Falk R, et al. Pathways to renal biopsy and diagnosis among patients with ANCA small-vessel vasculitis. Clinical Exp Rheumatol. 2013;31:S32-7.

2. Yacyshyn $E$, Johnson A, Rode M, Pagnoux C. Patient-driven online survey on the clinical manifestations and diagnostic delay of granulomatosis with polyangiitis. Joint Bone Spine. 2016;83(5):599-600.

3. Takala J, Kautiainen H, Malmberg H, Leirisalo-Repo M. Wegener's granulomatosis in Finland in 1981-2000: clinical presentation and diagnostic delay. Scand J Rheumatol. 2008;37(6):435-8.

4. Prior J, Ranjbar H, Belcher J, Mackie S, Helliwell T, Liddle J, et al. Diagnostic delay for giant cell arteritis - a systematic review and meta-analysis. BMC Med. 2017;15(1):1-12

5. Taimen, K, Mustonen A, Pirila L. The delay and costs of diagnosing systemic vasculitis in a tertiary-level clinic. Rheumatol Therapy. 2020.

6. Austin S, Wong Y, Uzzo R, Beck J, Egleston B. Why summary comorbidity measures such as the charlson comorbidity index and elixhauser score work. Med Care. 2015;53(9):e65-72.

7. Martin S, Ulrich C, Munsell M, Taylor S, Lange G, Bleyer A. Delays in cancer diagnosis in underinsured young adults and older adolescents. Oncologist. 2007;12:816-24.

8. Martin I, Young S, Sue-Ling H, Johnston D. Delays in the diagnosis of oesophagogastric cancer: a consecutive case series. BMJ. 1997:314(7079):467-467.

9. Richard M, Grob J, Avril M, Delaunay M, Gouvernet J, Wolkenstein P, et al. Delays in diagnosis and melanoma prognosis (II): the role of doctors. Int J Cancer. 2000;89(3):280-5.

10. Haroon M, Gallagher P, FitzGerald O. Diagnostic delay of more than 6 months contributes to poor radiographic and functional outcome in psoriatic arthritis. Ann Rheum Dis. 2014;74(6):1045-50.

11. Foster $H$, Eltringham M, Kay L, Friswell M, Abinun M, Myers A. Delay in access to appropriate care for children presenting with musculoskeletal symptoms and ultimately diagnosed with juvenile idiopathic arthritis. Arthritis Rheum. 2007;57(6):921-7.

12. Kumar K, Daley E, Carruthers D, Situnayake D, Gordon C, Grindulis K, et al. Delay in presentation to primary care physicians is the main reason why patients with rheumatoid arthritis are seen late by rheumatologists. Rheumatology. 2007;46(9):1438-40. 
13. McCausland K, White M, Guthrie S, QuockT, Finkel M, Lousada I, et al. Light chain (AL) amyloidosis: the journey to diagnosis. Patient Patient Cent Outcomes Res. 2017;11(2):207-16.

14. Springer J, Kermani T, Sreih A, Shaw D, Young K, Burroughs C, et al. Clinical characteristics of an internet-based cohort of patient-reported diagnosis of granulomatosis with polyangiitis and microscopic polyangiitis: observational study. J Med Internet Res. 2020;22(7):e17231.

\section{Publisher's Note}

Springer Nature remains neutral with regard to jurisdictional claims in published maps and institutional affiliations.
Ready to submit your research? Choose BMC and benefit from:

- fast, convenient online submission

- thorough peer review by experienced researchers in your field

- rapid publication on acceptance

- support for research data, including large and complex data types

- gold Open Access which fosters wider collaboration and increased citations

- maximum visibility for your research: over $100 \mathrm{M}$ website views per year

At BMC, research is always in progress.

Learn more biomedcentral.com/submissions 